\title{
RESENHA: Intersecciones: cuerpos y sexualidades en la encrucijada, Temas Contemporáneos
}

\author{
Rodrigo Rossi \\ Grupo de Estudos Territoriais / UEPG \\ mimdigo@gmail.com
}

Resenha: PLATERO, Raquel (Lucas) (Org). Intersecciones: cuerpos y sexualidades en la encrucijada - Temas Contemporáneos, Barcelona, Edicions Bellaterra. 2012.

O livro resenhado nessas linhas explora o diálogo coletivo realizado a partir do Estado Espanhol sobre a encruzilhada de lugares e identidades não-normativas. $\mathrm{O}$ livro, organizado por Raquel (Lucas) Platero, assume como objetivo expressar, desde a encruzilhada, as estratégias de pessoas e grupos que produzem performativamente e cotidianamente sexualidades não-normativas. Ao longo das páginas de Intersecciones, é contemplado um ambicioso e rico exercício epistemológico, político e calcado em experiências diversas que visa a constituição de um lugar de elocução e de um horizonte de expectativa política às pessoas lésbicas, trans e gays mais coerente com sua complexidade.

$\mathrm{Na}$ introdução, Platero apresenta o conceito de interseccionalidade como ferramenta de estudo da sexualidade. Para isso, apresenta o contexto de produção coletiva do livro, impulsionada no diálogo sobre sexualidades não-normativas e experiências concretas das pessoas investigadas. Realiza uma importante crítica ao uso banal do conceito como ligeira maneira de reconhecer a existência de identidades complexas, notadamente a partir da soma de adjetivos que contemplam facetas identitárias diversas. Platero sugere que pensemos mais adiante disso, dando relevância ao pioneirismo das feministas negras em evidenciar as fissuras do movimento feminista e o lugar de luta e resistência de grupos oprimidos pelo cruzamento de diferentes eixos de desigualdade. Além da contribuição teóricoepistemológica ligada ao conceito de interseccionalidade, o livro contribui com diferentes formas de operacionalizar o conceito, entrelaçando-o às perspectivas políticas que são instituídas pelas pessoas investigadas.

A primeira parte do livro é dedicada à publicação em castelhano de dois textos imprescindíveis a toda discussão sobre interseccionalidade. $\mathrm{O}$ primeiro é o épico Manifesto Feminista Negro escrito pelo Combahee River Collective, organização feminista negra e lésbica de importante atuação na Boston das décadas de 1970 e 1980. Trata-se de um documento chave para o entendimento e organização da luta feminista negra contemporânea. Indubitavelmente imprescindível a leitores(as) interessados(as) na compreensão de entre-lugares e na constituição de sujeitos e espaços, desde a encruzilhada em que se metem cotidianamente a partir de eixos de opressão envolvendo o gênero, raça, sexualidade e assim por diante.

O segundo texto que compõe a parte inicial do livro é o não menos clássico Cartografiando los márgenes. Interseccionalidad, políticas identitárias, $y$ violencia contra las mujeres de color, escrito por Kimberlé Willians Crenshaw. Tal autora é responsável por cunhar o termo interseccionalidade. No referido texto, agora 
traduzido ao castelhano, sugere que as vivências das mulheres negras não resultam apenas da observação dos atributos ligados à relação entre gênero e raça. Também explora as fissuras internas do feminismo demonstrando que a pseudo-unidade do movimento é responsável pela inibição da diversidade de vozes e da invisibilidade das experiências de mulheres negras.

No presente livro, a sexualidade é conscientemente eleita como um núcleo fundamental na operacionalização do conceito de interseccionalidade em consonância com as diferentes problemáticas de estudo construídas pelo grupo de autores e cujos textos compõem a Segunda Parte, intitulada: Intersecciones: diálogos contemporáneos sobre la sexualidad en el Estado Espanhol. Tais artigos contestam as normas hegemônicas e frequentemente naturalizadas referentes a sexualidade ao abordar experiências muito diversificadas. .

Como é explorado no primeiro artigo da Segunda Parte, de autoria de Guzman e Platero, que apresentam uma rica análise da relação entre as sexualidades não-normativas e as diversidades funcionais.

Em seguida, Bachiller e Platero apresentam um envolvente diálogo sobre os deslocamentos que a pessoas LGBTQ realizam para ter uma vida comunitária, na renegociação de significados que naturalizam masculinidade e feminilidade a partir das experiências butch/femme. Dessa conversa extraem a noção de 'diáspora queer' para refletir sobre seus espaços de vivência e suas próprias posições políticas.

O texto de Javier Saez apresenta a política de combate à AIDS, a partir de uma perspectiva interseccional que observa a cultura Bear como subcultura gay que ao se reapropriar da masculinidade, se posiciona na constituição de corpos paradoxais ou marginais.

Apoiado sobre um extenso trabalho de campo antropológico, David Berná Serna apresenta a cartografia das experiências de ciganos e ciganas homossexuais. $\mathrm{O}$ autor evidencia no texto as diferentes estratégias acionadas por ciganas e ciganos para vivenciar suas sexualidades diante das múltiplas formas de exclusão a que está submetida a etnia cigana e no jogo tenso entre a sexualidade não-normativa e a constituição de uma identidade grupal baseada na diferenciação sexual.

Platero e Berna apresentam, em seguida, uma entrevista com Eva Herrero sobre o tratamento dirigido às pessoas LGBT em centros de internamento de estrangeiros. A conversação desnuda a vivência precária de pessoas estrangeiras, sua classificação estigmatizante e os efeitos da experiência de privação da liberdade para pessoas LGBT que compõem um grupo em situação de vulnerabilidade no contexto da política de custódia de imigrantes 'ilegais'.

$\mathrm{O}$ artigo de Gerard Coll-Planas sobre as experiências de pessoas LGBT em espaços carcerários apresentando uma série de componentes que entrelaçam o regime de privação da liberdade e os modos em que nele expressam suas identidades sexuais e de gênero não-normativas. $\mathrm{O}$ estudo apresenta $\mathrm{O}$ espaço carcerário como constituído por interrelações entre sexualidades, gênero, classe social, nacionalidade, capital social, bem como outros componentes que influenciam um sistema relacional de privilégio e exclusão.

Também explorando o contexto carcerário, Virginia Villaplana revela em seu texto as experiências educativas e artísticas de pessoas trans e homossexuais estrangeiras, dando ênfase ao lugar de discurso das pessoas entrevistadas para questionar as teorias e políticas dominantes, bem como refletir sobre posicionalidade.

Por fim, Cécile Stephanie Stehrenberger apresenta uma análise da Seção Feminina, 
órgão governista de apoio ao regime fraquista no Estado Espanhol, a partir dos espetáculos de coral e de dança. A autora evidencia uma complexa interação entre o discurso patriarcal, colonialista e nacionalista que foi fundamental como dispositivo de legitimação da ditadura e dos valores ligados à opressão de gênero, sexualidade e colonialidade.

O livro organizado por Platero ilumina uma perspectiva interseccional e dialógica que não somente dá visibilidade a experiências concretas de opressão ligadas a sexualidade. Também expressa uma linha de tensão no âmbito teórico-metodológico do conceito de interseccionalidade. $\mathrm{O}$ conceito de interseccionalidade ganhou notoriedade e relevância não só à temática e à própria luta do movimento das mulheres negras, mas a todo um conjunto de intelectuais e ativistas que o integraram na perspectiva de dar visibilidade às identidades complexas, eixos de opressão e desigualdades, bem como, para refletir sobre as posições políticas que compõem dada realidade estudada ou de intervenção. O livro, portanto, convida seus leitores e leitoras a assumir como potencial o embrião político contestatório e revolucionário ligado ao conceito de interseccionalidade. 